$15^{\text {th }}$ International Conference on

AEROSPACE SCIENCES \& AVIATION TECHNOLOGY,

$\boldsymbol{A S A T}$ - 15 - May 28 - 30, 2013, Email: asat@mtc.edu.eg,

Military Technical College, Kobry Elkobbah, Cairo, Egypt,

Tel: +(202) 24025292 -24036138, Fax: +(202) 22621908

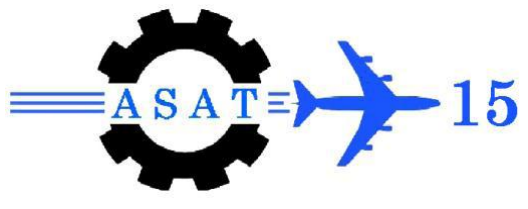

\title{
Multi-Wheeled Combat Vehicle Tire Modeling on Rigid and Soft Terrain
}

\author{
$\left\{\text { H. Ragheb }{ }^{*}, \text { M. El-Gindy }{ }^{\dagger}, \text { H. A. Kishawy }\right\}^{\ddagger}$
}

\begin{abstract}
Multi-wheeled off-road vehicles performance depends not only on the total engine power but also on its distribution among the drive axles/wheels. In turn, this distribution is largely regulated by the drivetrain layout and its torque distribution which is constrained by the interaction between the wheels and the terrain (rigid or soft soil).

In this paper three-dimensional, non-linear Finite Element Analysis (FEA) off-road tire models on rigid and soft terrain were developed using PAM-CRASH and the general trends of vertical load-deflection, cornering characteristics and aligning moment on rigid terrains are compared with published measured data of a similar tire for validation purposes.

Non-linear tire look-up tables for rigid and soft terrain were developed based on FEA off-road tire simulation results and used for vehicle simulation using the multi-body dynamics code TruckSim. The predictions of vehicle handling characteristics and transient response during lane change test on rigid road at different vehicle speeds were compared with simulation results for same vehicle configuration using real experimental tire data. Simulation results are compared on the basis of vehicle steering, yaw rates and accelerations. The published US Army validation criteria has been used to validate simulation results.
\end{abstract}

Keywords: Off-road, Multi-wheeled, dynamic model validation, FEA, PAM-CRASH, TruckSim, validation methodology, handling characteristics.

\section{Introduction}

Muli-Wheeled vehicles that are used mainly for military or for special purposes have to fulfill several key requirements. One of these requirements concerns its off-road mobility. Off-road terrains are characterized by deformable irregular surfaces with abrupt slopes and obstacles of the distinctive nature. It is commonly recognized that, the interaction between wheeled vehicles and soft terrain was complex and strongly dominated by the terrain's mechanical properties. Furthermore, some soils can behave excessively in terms of sinkage and slippage according to the applied wheel normal load and driving torque.Mechanics of tire-soil interaction is one of the essential aspects in off-road vehicle studies. The interaction between pneumatic tire and deformable soil is very complex and includes many effects such as sinkage, multi-pass and slip sinkage. Driven tire performance is usually characterized by its thrust, resistance to motion, sinkage, slip, driving torque and angular speed. One of the prime interest to all researches and designers of off-road vehicles is how to accurately predict these parameters.

\footnotetext{
Hossam.Ragheb@uoit.ca

Moustafa.El-Gindy@uoit.ca

Hossam.Kishawy@uoit.ca

$\S$ University of Ontario Institute of Technology (UOIT), 2000 Simcoe Street North, Oshawa, Ontario, L1H 7K4, Canada.
} 
In recent years, a variety of methods have been proposed to study the interactions of pneumatic tires with deformable soils [1]. They range from entirely empirical approaches to highly theoretical ones, Figure 1.

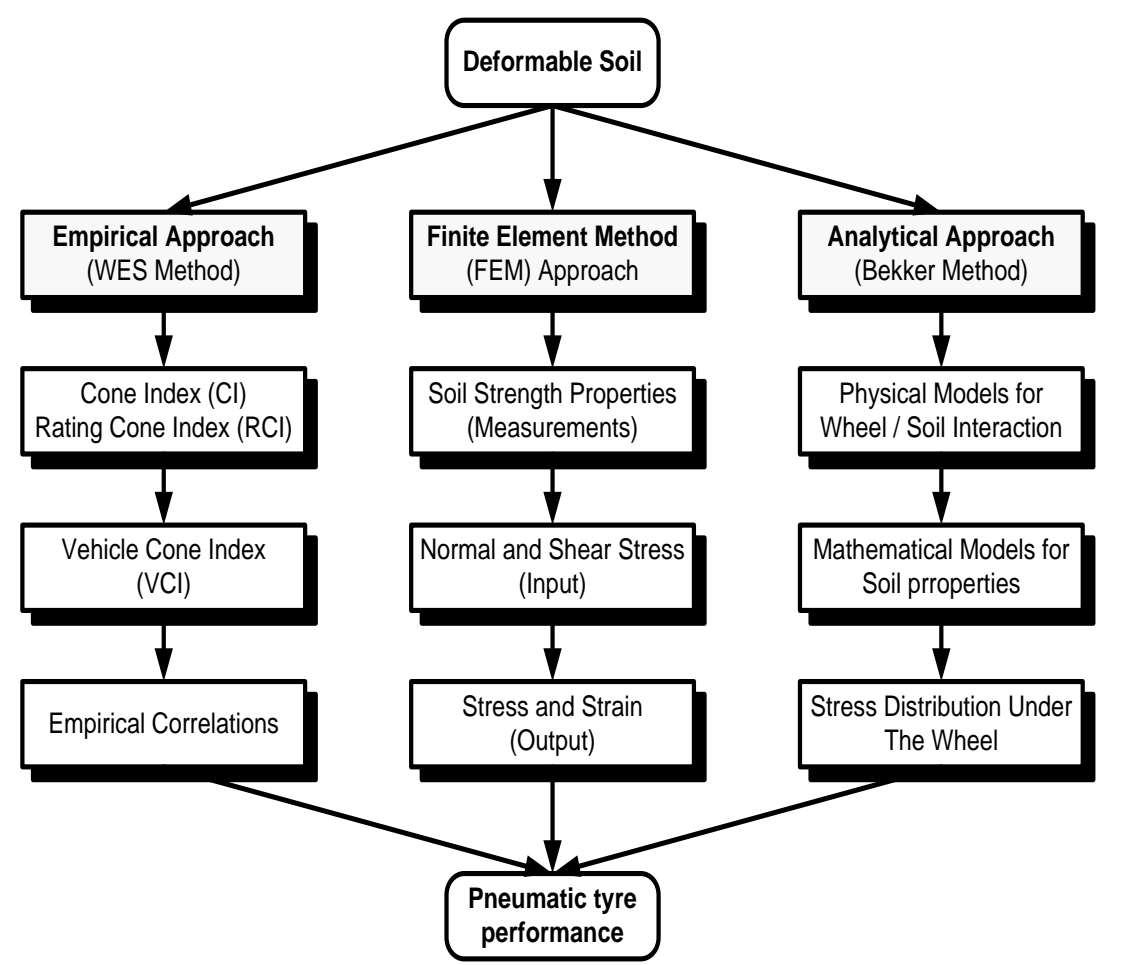

Fig. 1 Common approaches used to study the mechanics of wheel-soil interaction

Accordingly, tire companies conduct many physical laboratory tests such as vertical stiffness and damping constant tests, cornering tests, and durability tests in order to examine tire performance. Generally, the measurement tests in laboratory significantly consume time and cost. Testing equipment, their arrangement, and data acquisition and analyses need high skills and long testing time. So, many investigators have tried to construct alternative tire testing environments in the last few years. Fortunately, current computer technology facilitates the development of new tire models and most of the laboratory tire tests can be virtually duplicated. Even tire tests that cannot be performed in laboratory, such as high speed and/or loading operations.

Extensive research has been conducted to develop efficient but accurate pneumatic tire, and soil models to improve upon predictions of off-road vehicle dynamics through mathematical modeling and simulation. Soil modeling is useful for designers of driveline and braking systems as well as the prediction of motion and stability of off-road vehicles. Because traction, braking performance, and handling properties vary greatly with the terrain on which the vehicle is driven, it is important to model the tire-soil system accurately. While force generation between the tire and pavement is well understood, tire-soil interaction modeling is far behind in development.

Because tire-soil interaction field tests are both inherently costly and difficult to control, the cost efficient finite element analysis method (FEA) has been used for decades for conducting such tests. Likewise, FEA has been used to study a variety of aspects of terramechanics with great success. In 1978 Yong et al. applied the FEA to model performance of flexible pneumatic tires on soft-soil [2].In conjunction with the analytical predictions, laboratory tests 
were conducted to measure tire carcass stiffness and drawbar pull as a function of inflation pressure. This work concluded that the FEA can be used to predict tire-terrain interaction accurately if the load-deformation behavior for a wheel is known. Also, in 1997 Hiroma et al. developed an FEM code to predict stress distribution under a rolling wheel and tire tractive performance [3]. Predictions of the stress distribution under the wheel and the coefficient of traction were compared with measurements and found to be reasonable. The concluding remark made by Hiroma et al. stated that, for low slip conditions, the finite element method could be used to predict the coefficient of traction.

Wallentowitz et al. compared both testing and simulations in determining static and dynamic tire characteristics [4]. Tire models were found to be either too simple to model dynamic behavior or were too time-consuming to be practical. A dynamic tire test rig was designed and installed at the Institute für Kraftfahrwesen Aachen, Germany with the purpose of providing data to improve tire models. Over a range of slip angles, the lateral forces, selfaligning torques, and sinusoidal steering characteristics of automobile tires were measured. This data is very useful for model tuning and validation purposes when comparing to trends obtained from FEA simulations.

Tönük and Ünlüsoy performed detailed modeling of a radial tire using finite element analysis methods [5]. The model consists of five types of structural components; tread sidewall, textile belts (tire carcass), steel belts, and bead filler. Two layers of steel belts are included and oriented at \pm 20 degrees. Cornering forces from $0^{\circ}$ to $7^{\circ}$ slip and vertical loads of $1500 \mathrm{~N}$ to $4500 \mathrm{~N}$ were measured experimentally and simulated. The model was found to predict cornering forces to an acceptable degree of accuracy. Finite element models were determined to be a valuable resource during the design phase of tires.

Chang and El-Gindy developed tire-drum model to predict tire standing waves and tire free vibration modes. The visualized simulations of the standing waves phenomenon were carried out for the first time. The determination of the tire in-plane free vibration modes was achieved by recording the reaction force of the tire axle at longitudinal and vertical directions when the tire rolling over a cleat on the road. The results were compared to more than ten previous studies and showed good agreement [6].

Mehmet developed a finite element model, which combines accuracy together with substantially reduced computational effort, to obtain the cornering force characteristics for rotating pneumatic tires [7]. For cord reinforced rubber sections such as the body plies and breaker belts, continuum elements with orthotropic material properties are used to improve solution times. The finite element model is used to obtain the cornering force characteristics of a tire, simulating the experiments on a tire test rig where the tire rotates on a flywheel. Results from both models are compared with each other and with the experimental results. It is concluded that the developed model provides results at least as accurate as the previously published models with a clear superiority in stability of solution.

Fervers studied radial-ply tire-soil interaction by constructing a 2-D FEA model using ABAQUS [8]. The ABAQUS Drucker-Prager material definition with extended CapPlasticity was used for modeling two different soils: wet, loose loam with high cohesion and dry sand with low cohesion. The tire was loaded and given constant longitudinal speed with no slip at two extreme inflation pressures for the two types of soil. Likewise, Chae et al. developed a full nonlinear FEA model of a radial-ply truck tire by using explicit FEA simulation software, PAM-SHOCK. The tire model was constructed to its extreme complexity with solid, layered membrane, and beam elements. Also, a rim model was 
included and rotated with the tire with proper mass and rotational inertial effects. The predicted tire characteristics and responses, such as vertical stiffness, cornering force, and aligning moment, correlated very well to physical measurements [9].

Allen et al. developed a simplified Finite Element Analysis (FEA) truck tire model and used it to examine the interaction between the tire and various types of terrain. Soft terrain such as hard soil and dry sand is modeled using solid, elastic-plastic elements [10]. The general trends of vertical and longitudinal forces and normal and shear stress distributions in the soft soil are compared with published data for preliminary validation. The cornering characteristics on both rigid and soft soil terrains are also predicted and compared. Additionally, a detailed FEA truck tire is introduced as the next phase of this work.

Slade et al. developed new off-road rigid ring model from the FEA Regional Haul Drive (RHD) tire and soil (dense sand in this study) which could be used to replace the FEA model for all full vehicle simulations and to further save CPU time and reduce costs. This initial version of the off-road rigid ring model will be subjected to extensive tune up using various types of soils and various operating conditions [11].

Han et al. developed a 3D tire-soil FEA model in ABAQUS® specifying 175R14 tire and soil interaction [12]. The static-steady tire-soil model is analyzed for studies on the stress, strain and deformation of tire and soil under a certain sinkage taking into the consideration of tire structure and soil constitution. It also obtains the relationship between load and contact pressure which will be helpful for the further tire-soil study under serious condition.

Korunović et al. developed a finite element model for FEA of a tire rolling on a drum, which demonstrates the flexibility of CAD based meshing approach introduced by the authors [13]. The results of the analyses conducted on the model have successfully been compared to experimental ones, confirming FE model validity. The differences between experimental and numerical results were decreased after the calibration of friction coefficient had been performed. In such a way the further improvement of the existing model was achieved. The presented FE tire model and associated analyses are used for performing parametric studies within the tire design process, helping the tire designer to quickly find the optimal values of tire design parameters. The tire design process is thus shortened and the same time greater predictability and improvement of tire performance are achieved.

\section{FEA Off-Road Tire Model}

In this research work, tread patterns of the 4-groove off-road tire has been developed to represent the Off-road12.00R20 XML TL 149J tire tread $[14,15]$. The developed tire model has an asymmetric tread pattern to prevent tire from trapping and holding stones in the tread. The complicated design was simplified to contain the fundamental elements while minimizing modeling and processing time. Straight edges were used wherever possible to replace curves for the shape of the lugs and the grooves between the lugs. The max tread depth is modeled as $30 \mathrm{~mm}$. Each lug was simplified as rectangular with angled sides, and the grooves between lugs are simple V's. Solid tetrahedron elements with Mooney-Rivlin material properties were chosen for the tread. Figure 2 shows the final FEA model tread design. The material property for the two different layers (one for rubber and the other for steel cords) and the orientation of each layer is assigned appropriately to model the rubber tire carcass and belts. In this case, the cords in the carcass run radially in the carcass from bead to bead. 

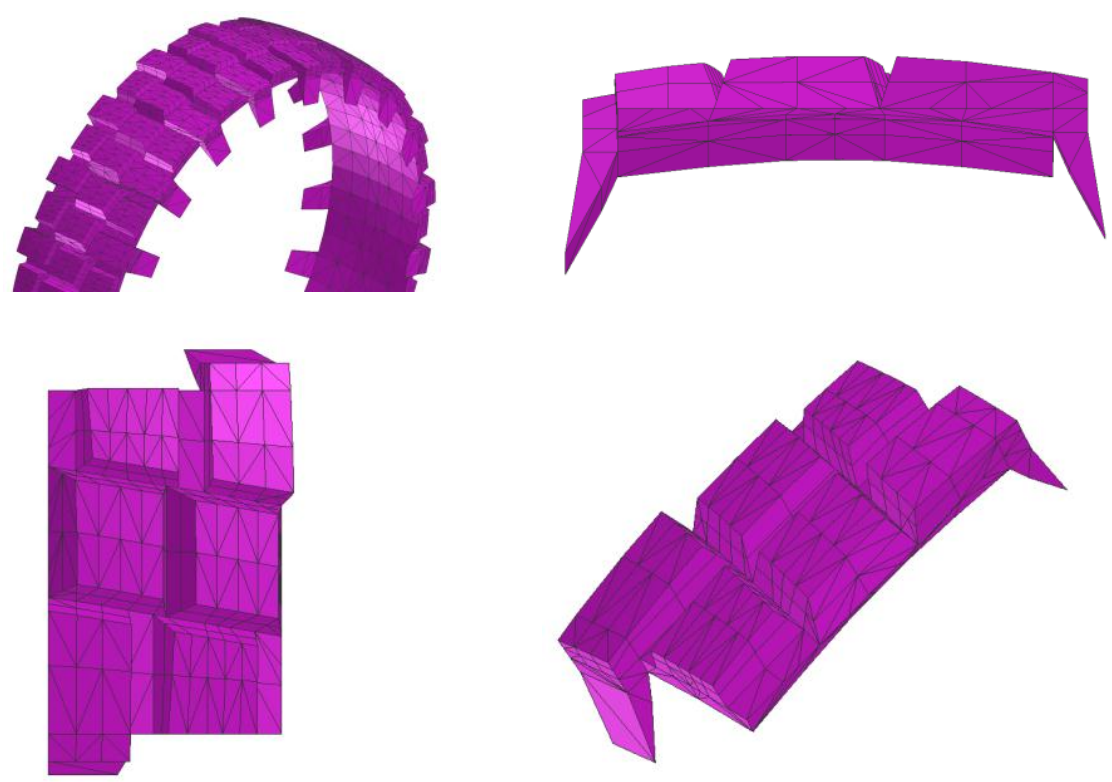

Fig. 2 Tread design as viewed from different views

The tire model is constructed using the following finite element components:

- 25 Parts,

- 9,920 nodes,

- 1,800 layered membrane elements,

- 13,280 solid elements,

- 120 beam elements,

- 25 material definitions, and

- 1 rigid body definition.

The advantages of this tire model are its computational efficiency and stability. Figure 3 shows the basic dimensions of the finite element tire model. Figure 4 shows a comparison between the actual tire and the FEA tire model. Technical data for the off-road tire model is shown in Table 1. The Mooney-Rivlin material properties for the solid tread and under-tread elements are shown in Table 2.
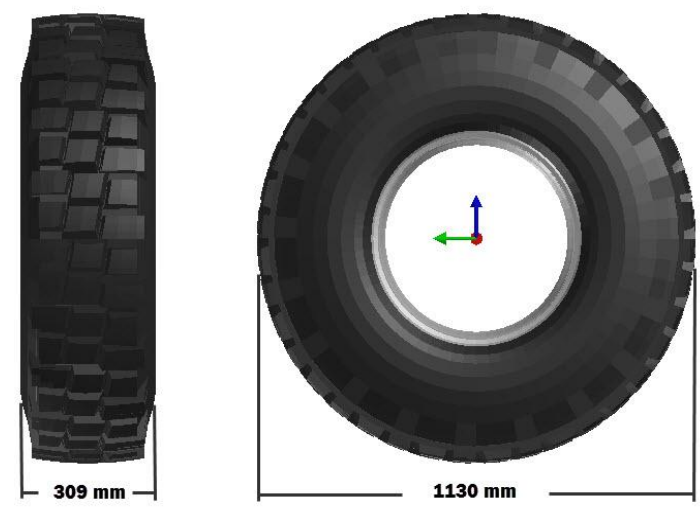

Fig. 3 Tire Basic Dimensions 


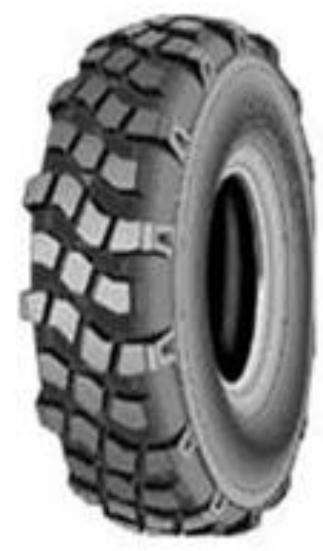

a)

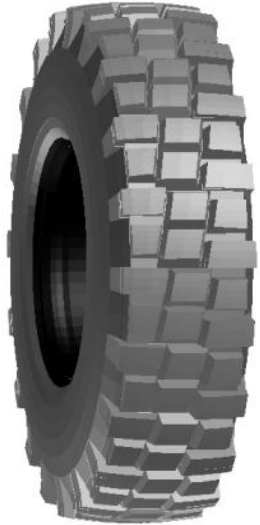

b)

Fig. 4 Comparison of actual (a) and detailed FEA model

(b) combat vehicle tire

Table 1 FEA Tire Model Technical Data

\begin{tabular}{l|c|c}
\hline \hline Max. Tread depth & $30 \mathrm{~mm}$ & 1.181 in \\
\hline Rim Width & $283.4 \mathrm{~mm}$ & 11.16 in \\
\hline Rim Weight & $31.2 \mathrm{~kg}$ & $68.78 \mathrm{lbs}$. \\
\hline Tire Weight & $55.3 \mathrm{~kg}$ & $121.92 \mathrm{lbs}$. \\
\hline Total Tire Weight & $86.5 \mathrm{~kg}$ & $190.7 \mathrm{lbs}$. \\
\hline Overall Width & $309 \mathrm{~mm}$ & $12.16 \mathrm{in}$ \\
\hline Overall Diameter & $1130 \mathrm{~mm}$ & $44.48 \mathrm{in}$ \\
\hline
\end{tabular}

Table 2 Material properties for tread and under-tread solid rubber elements

\begin{tabular}{l|c|c}
\hline \hline Tire Component & Under-tread & Tread \\
\hline Density $\left(\mathrm{kg} / \mathrm{m}^{3}\right)$ & 596.2 & 693.3 \\
\hline 1st Mooney-Rivlin coeff. $(\mathrm{C} 10)$ & 0.51 & 0.67 \\
\hline 2nd Mooney-Rivlin coeff. (C01) & 1.86 & 2.46 \\
\hline Poisson's ratio & 0.49 & 0.49 \\
\hline \hline
\end{tabular}

\subsection{Tire Model Validation}

The tire model will be used to determine the tire-soil characteristics that are required to build a new off-road tire model based on FEA results. So, the tire model needs to be validated by checking whether it shows real tire characteristics. For the validation, different tire simulations were conducted at various operating conditions (load, inflation pressure and slip angles). The results of the validation tests are compared with physical measurements.

\subsubsection{Static vertical deflection on flat surface}

The tire model was subjected to extensive sensitivity analysis to tune up the mechanical properties of various material components in order to achieve reasonable load-deflection characteristics in comparison with measured data. In order to obtain the correct model characteristics, it is necessary to adjust the thickness (h), the Mooney-Rivlin coefficients of rubber compounds of the tread and under-tread (C10 and $\mathrm{C} 01)$, and the modulus of elasticity (E) of both the sidewall and the under-tread of the tire model. The final tire model with adjusted material parameters is shown under a $55 \mathrm{kN}$ static load with an inflation pressure of 6bars in Figure 5. 


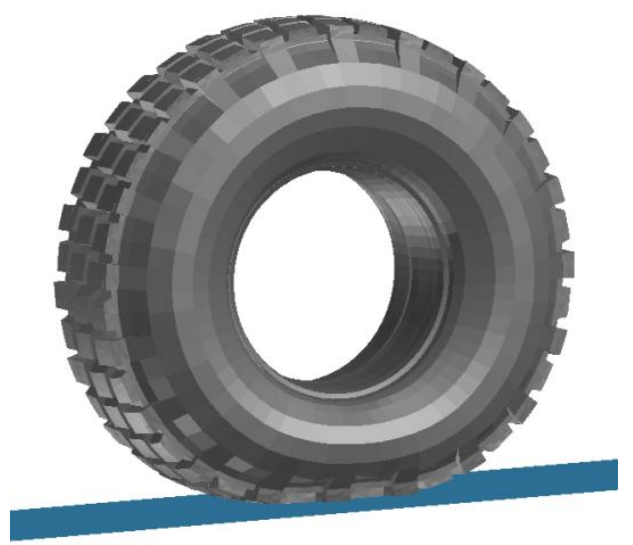

\section{Fig. 5 FEA Off-road tire model under 55 kN load and 6 bar inflation pressure}

Figure 6 shows the static deflection curve from actual tire data and the predicted results using the FEA tire model over a wide range of loads and inflation pressures. The actual tire data was obtained from published measurement data for a tire similar to the Off-road 12.00R20 XML TL 149J. Reasonable agreement can be observed, and this data is presented as model validation.

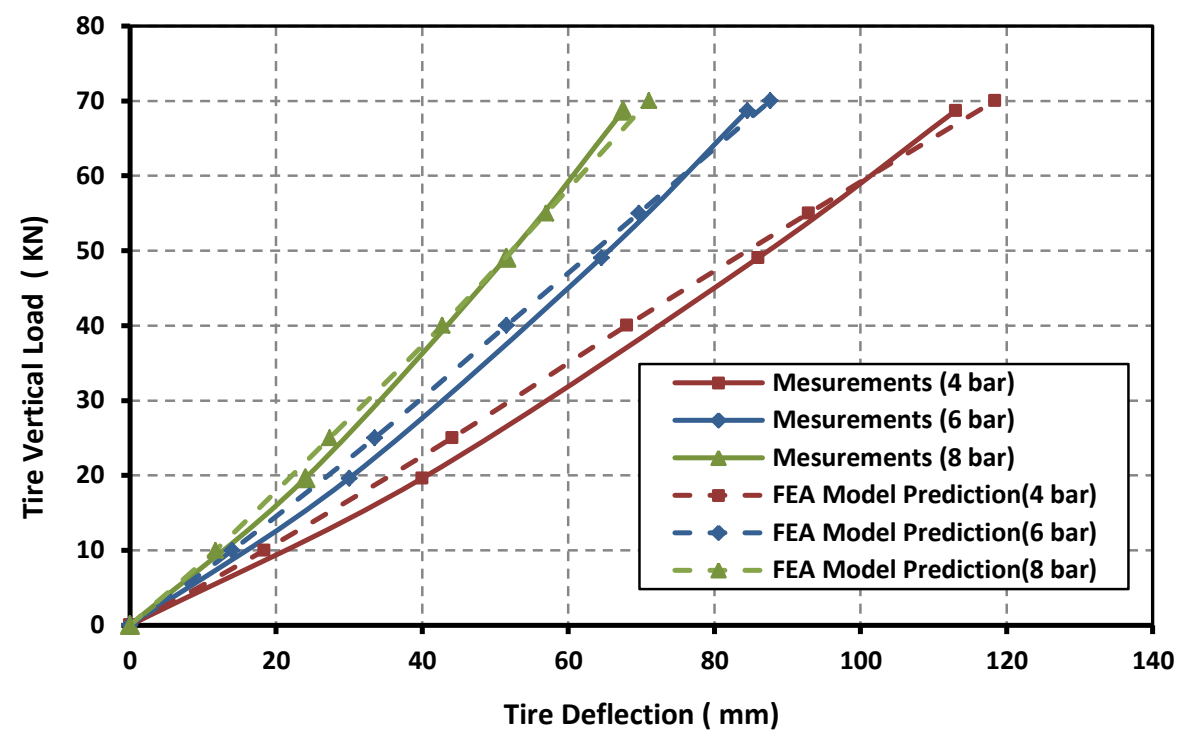

Fig. 6 Load-deflection curve at different inflation pressures

\subsubsection{First mode of vibration test}

A tire and cleat-drum test was conducted to determine the first mode of vertical free vibration. Figure 7 shows the tire running on the virtual cleat drum test rig. A test was run for a tire load of $26.7 \mathrm{kN}$ and an inflation pressure of 7.58 bars.

A Fast Fourier Transform (FFT) algorithm was applied to the vertical reaction force at the tire spindle to obtain the frequency analysis shown in Figure 8. Peaks in the figure represent free vibration modes. The drum rotates at an angular velocity of $15 \mathrm{rad} / \mathrm{sec}$ which results in about a $2.5 \mathrm{~Hz}$ excitation due to the cleat impact. This impact is shown by the first peak from around 1 to $4 \mathrm{~Hz}$ in the FFT. The second peak at approximately $46 \mathrm{~Hz}$ corresponds to the first vertical free vibration mode. The available experimental data for the first vertical free 
vibration mode for passenger cars tires lies in the range of 60-80 Hz [16].For the developed FEA off-road tire which has larger diameter and softer materials comparing to passenger car tires, its sidewalls will absorb more vibrations instead of transferring it to the tire center. So, it can be expected to have values lower than $60 \mathrm{~Hz}$.

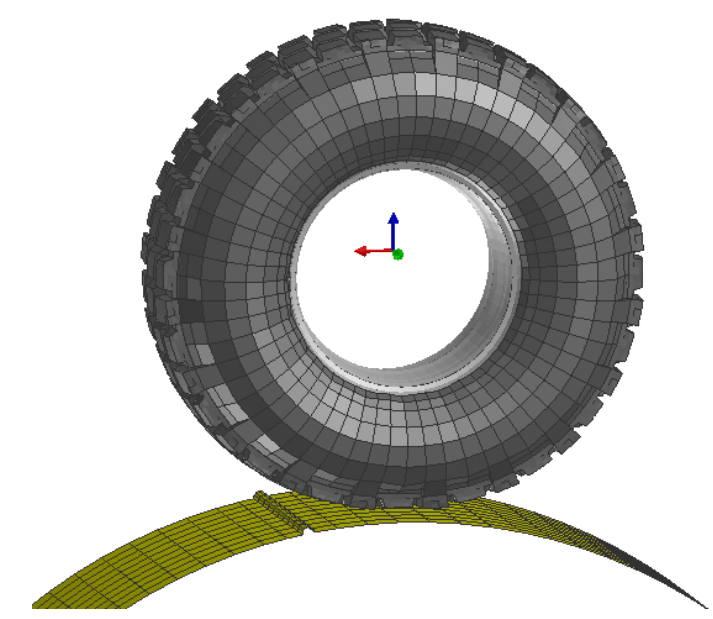

Fig. 7 FEA model on cleat drum

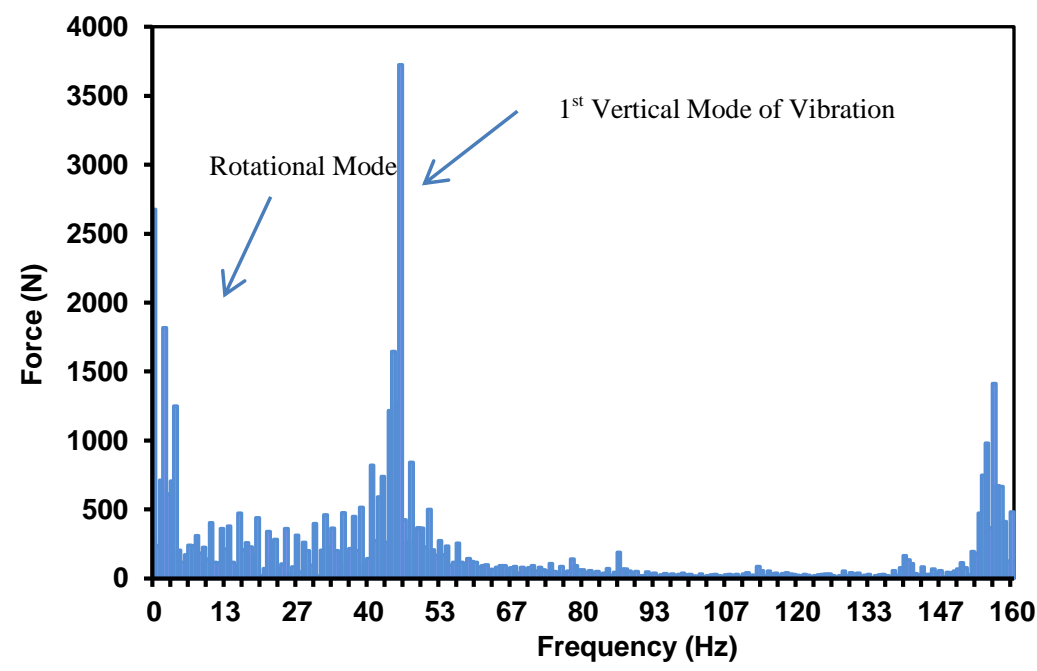

Fig. 8 FFT Result of Vertical Reaction Force at Tire Spindle at $26.7 \mathrm{kN}$ vertical load and 7.58 bar inflation pressure

\subsubsection{Cornering characteristics on flat surface}

The cornering test is virtually conducted to examine the characteristic cornering performances of the FEA off-road tire model. The tire model is inflated at a pressure of 7.2 bars and loaded vertically up to $63.75 \mathrm{kN}$ at the spindle of the tire model. Then, the tire model is steered at slip angles $(\alpha)$ up to $6^{\circ}$. A flat road is moving at constant speed of $10 \mathrm{~km} / \mathrm{h}$ under the tire to rotate the tire model. Figure 9 shows the cornering simulation at slip angles of $2^{\circ}, 4^{\circ}$ and $6^{\circ}$ and the lateral deformation of the tire at the contact area with the road surface. 


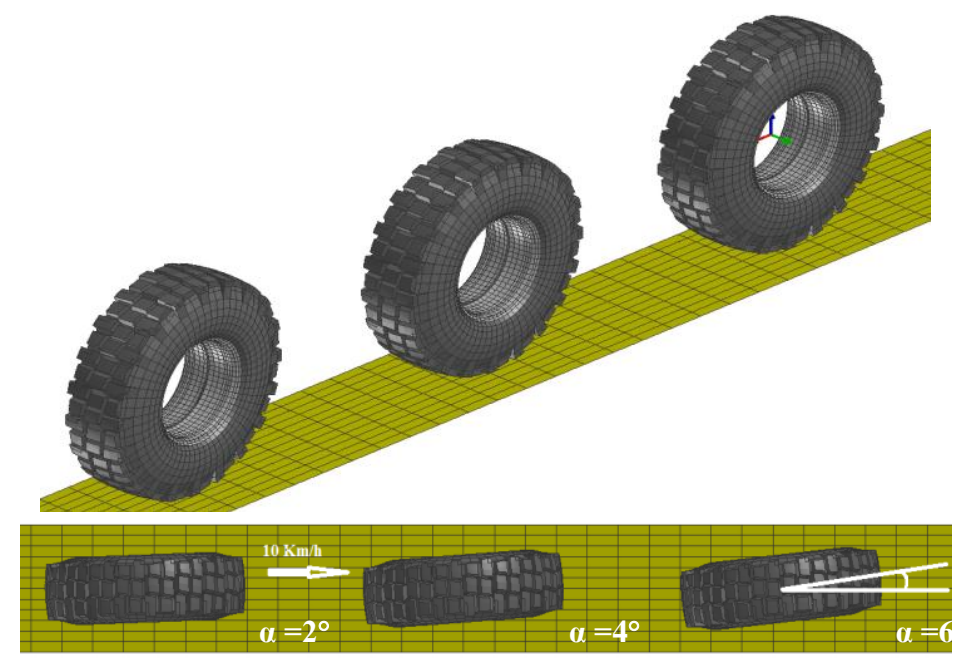

Fig. 9 Cornering simulation for the FEA off-road tire at slip angles of $2^{\circ}, 4^{\circ}$ and $6^{\circ}$

The predicted cornering forces with respect to different slip angles up to $6^{\circ}$ at vertical loads of $15.94 \mathrm{kN}, 31.88 \mathrm{kN}$, and $63.75 \mathrm{kN}$ are plotted in Figure 10 and compared with the published measurement data from the tire manufacturer. Another important cornering characteristic parameter, such as the aligning moment, is also predicted with respect to various slip angles $(\alpha)$, and compared with published measurement data as seen in Figure 11.

In the regions of slip angles from $0^{\circ}$ to $6^{\circ}$, the predicted aligning moments show good agreement with the measurements at the lower two tire load cases. For slip angles $(\alpha)>3^{\circ}$, considerable discrepancies are observed. The discrepancies are considered to be due to the differences in cross-sectional shapes, contact areas, and tread patterns between the FEA and real off-road tire.

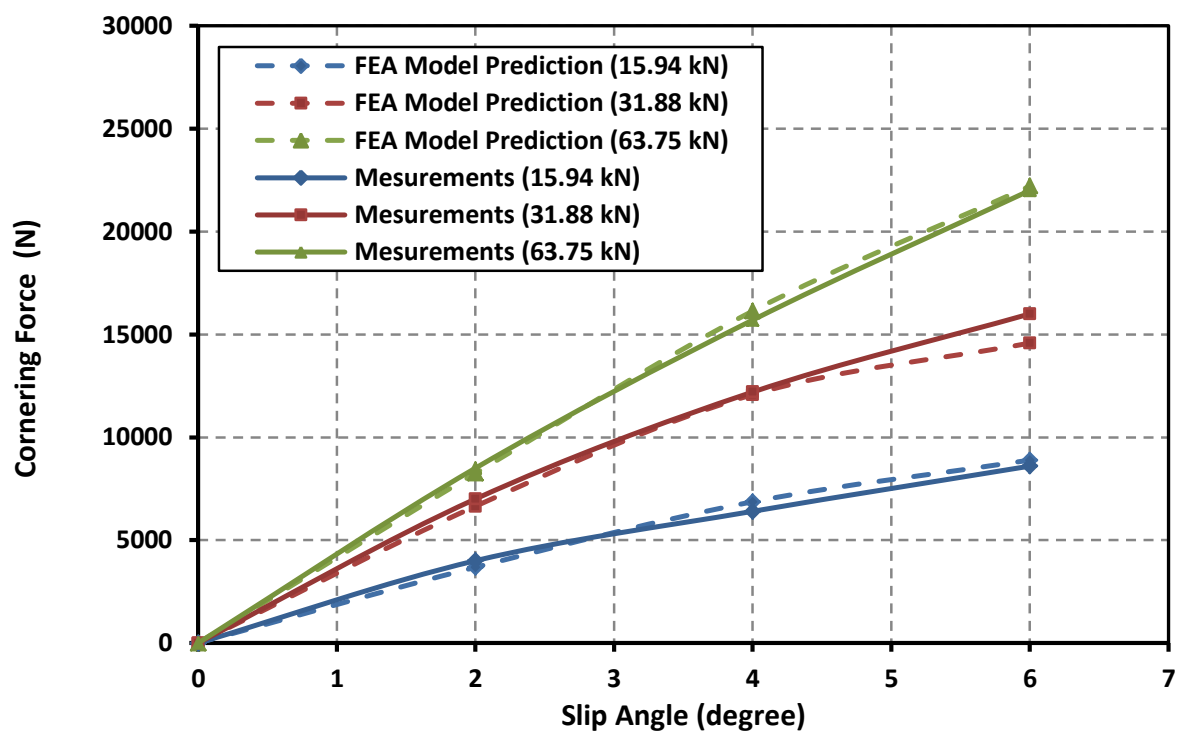

Fig. 10 Cornering force-slip angle curve at different vertical loads 


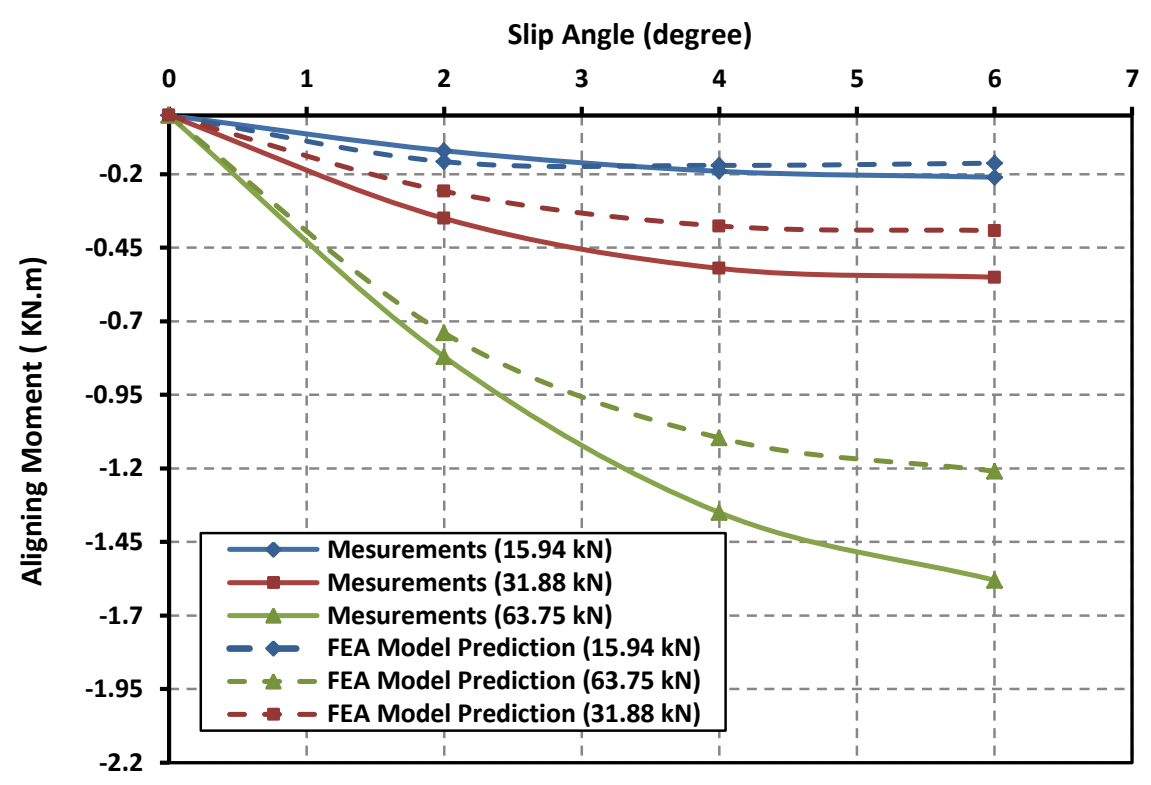

Fig. 11 Aligning moment-slip angle at different vertical loads

\subsection{Soil Model Representation}

A new type of soil was created using an elastic-plastic solid material (PAM-CRASH Material 1). The meshing is performed in PAM-CRASH by splitting a large solid block into $25 \mathrm{~mm}$ by $25 \mathrm{~mm}$ by $25 \mathrm{~mm}$ elements. The tire-to-soil contact is defined as a node to segment contact with a friction coefficient of 0.8 . The new soil modeled is a clayey soil. The material properties for this new soil are listed in Table 3. It should be noted that the material properties are chosen by using the mean value of the ranges given by the U.S. Department of Transportation, Federal Highway Administration.

Table 3 Material properties for the new soil.

\begin{tabular}{c|c|c|c|c|c}
\hline \hline Soil Type & $\begin{array}{c}\text { Elastic } \\
\text { Modulus, } \\
\text { E (MPa) }\end{array}$ & $\begin{array}{c}\text { Bulk } \\
\text { Modulus, } \\
\text { K (MPa) }\end{array}$ & $\begin{array}{c}\text { Shear } \\
\text { Modulus, } \\
\text { G (MPa) }\end{array}$ & $\begin{array}{c}\text { Yield } \\
\text { Stress, } \\
\text { Y (MPa) }\end{array}$ & Density, \\
$\rho\left(\right.$ ton $\left./ \mathrm{mm}^{3}\right)$ \\
\hline Clayey Soil & 24 & 15 & 9 & 0.016 & $1.60 \mathrm{E}-09$ \\
\hline \hline
\end{tabular}

\subsubsection{Validation using pressure-sinkage test}

Soil characteristics can be compared and validated by looking at the relationship between applied pressure and soil sinkage. This type of testing is discussed in detail by Wong [17]. The pressure-sinkage test is done by applying a known pressure over a circular plate placed on the soil and observing how far the plate sinks into the soil. The new soil is compared to the terrain values, given in Table 2.3 from Wong [17] using the Bekker formula (Equation 1).

$$
p=\left(\frac{k_{c}}{b}+k_{\varphi}\right) z^{n}=k z^{n}
$$

Figure 12 shows the pressure-sinkage simulation of the soil with a rigid $15 \mathrm{~cm}$ circular plate. Figure 13 depicts the effect of normal pressure on tire sinkage. As can be seen in the figure a comparison between the predicted and previously published measurements confirm the validity of the proposed model. 


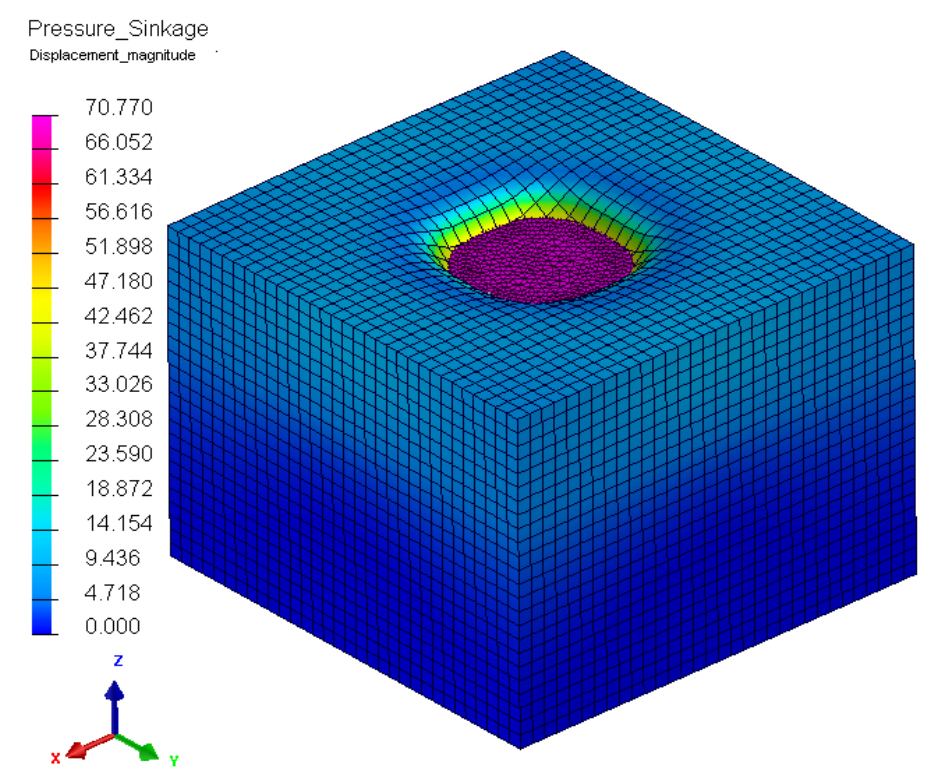

Fig. 12 Virtual measurements of pressure-sinkage using a $15 \mathrm{~cm}$ circular plate on the new soil with a pressure of 2 bars

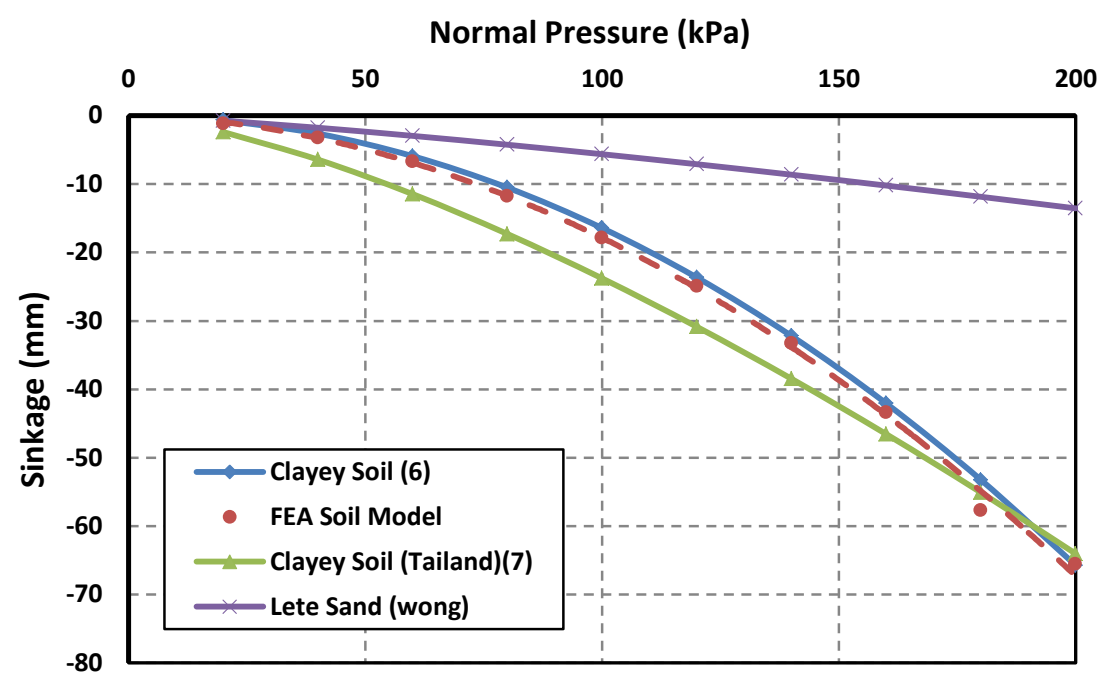

Fig. 13 Effect of Normal pressure on sinkage

\subsection{FEA Off-Road Tire Model on Soft Soil}

After validation of the new FEA off-road tire model, as well as the soil model, it was used to evaluate tire performance on soft soil to facilitate the development of a set of empirical equations that can be used to represent the tire-soil interaction characteristics.

In addition, the FEA off-road tire models used to investigate the multi-pass behavior of the wheels running on soft terrain and its effect on vehicle mobility performance. The steering characteristics of the multi-wheels are also predicted.

The objectives in this part are:

- Calculate tire vertical stiffness on soft soil.

- Calculate rolling resistance on soft soil for multi-wheels.

- Calculate steering characteristics on soft soil for multi-axle steering. 


\subsubsection{Tire vertical stiffness on soft soil}

The off-road tire model was inflated at three different inflation pressures of 3.79, 7.58 and 11.37 bar and loaded at the spindle of the tire model on soil surface instead of the flat road surface as seen in Figures 14 and 15. After the tire model reaches stability, the steady-state vertical deflection of the tire model and soil is recorded to calculate tire and soil stiffness as seen in Figure 16.

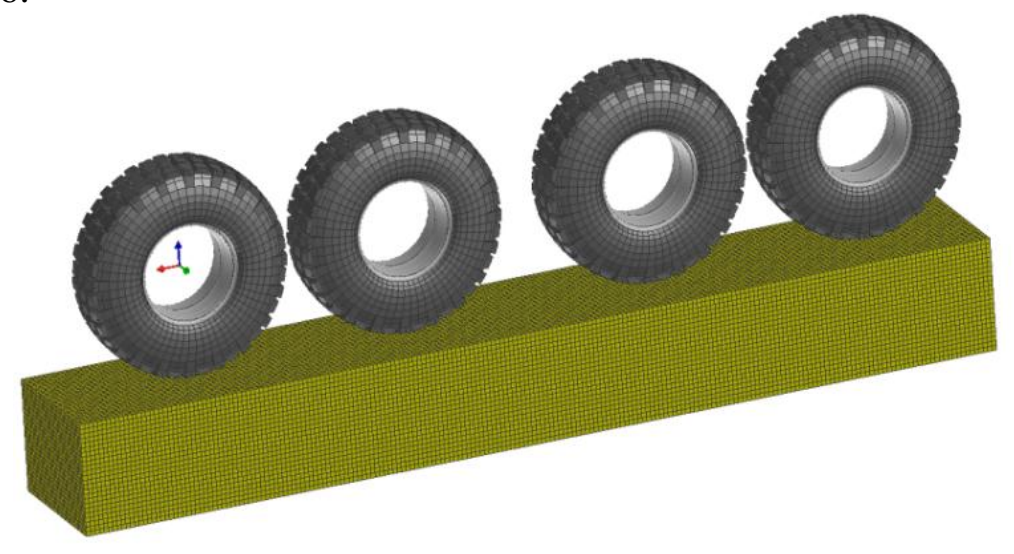

Fig. 14 FEA off-road tires on soil surface

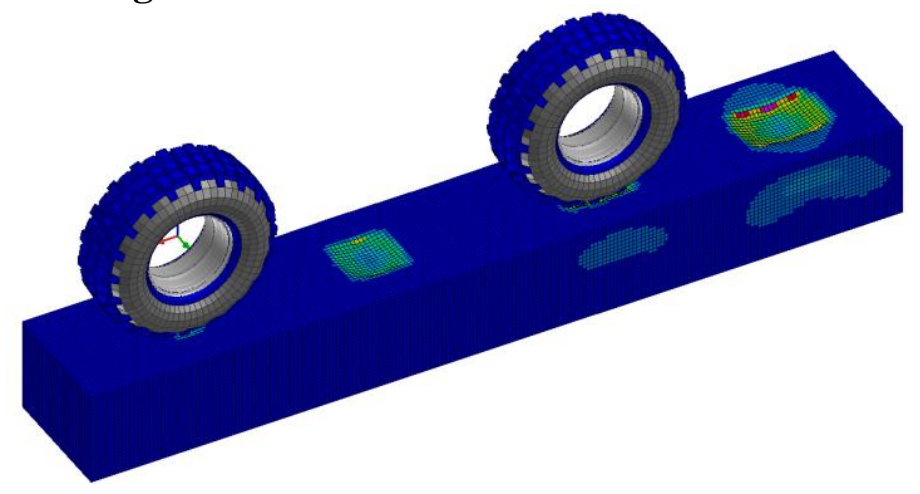

Fig. 15 FEA off-road tires on soil surface simulation

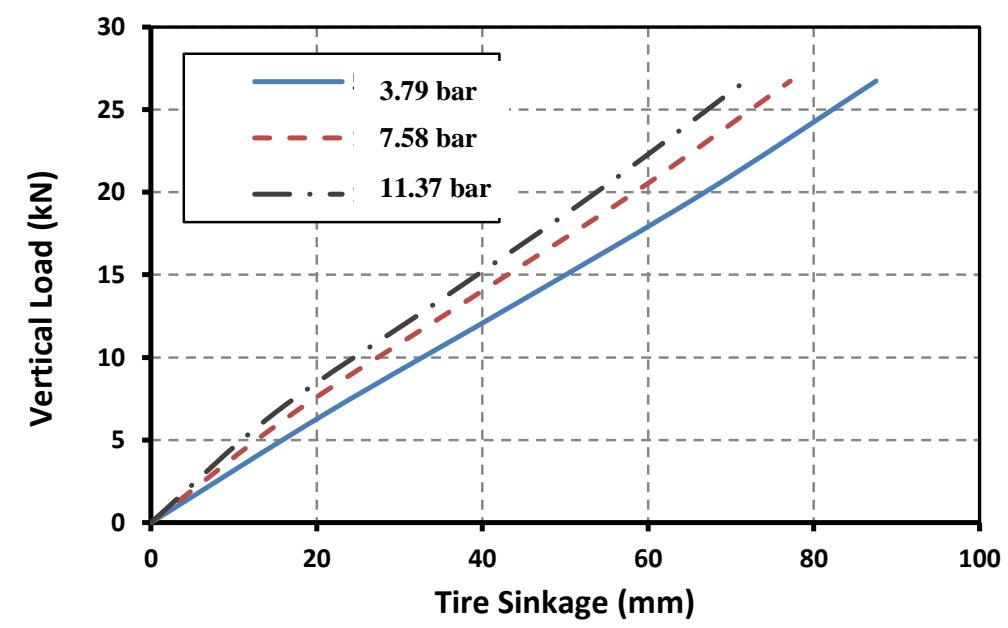

Fig. 16 Load-sinkage curve under different inflation pressure

\subsubsection{Rolling resistance on soft soil for multiple wheels}

For the rolling resistance of multi-wheels (4 tires) running on soil surface, the off-road tire model is inflated at three different inflation pressures of 4, 6 and 8 bar and loaded with three vertical loads of 6,18 and $48 \mathrm{kN}$ at the spindle of the tire model on soil surface as seen in Figure 17. 


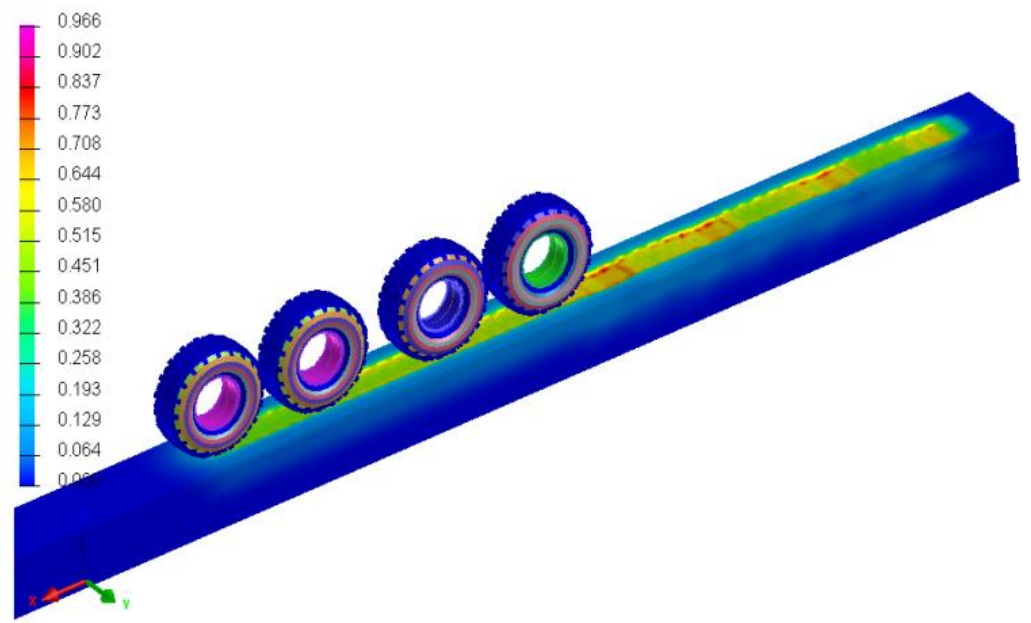

Fig. 17 FEA off-road tires (4 tires) running on soil

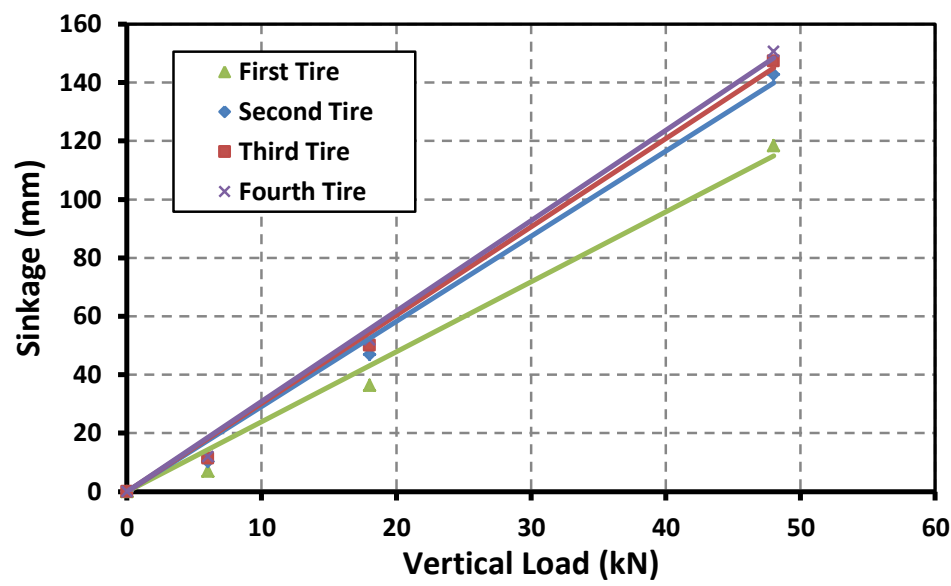

Fig. 18 FEA off-road tires (4 tires) sinkage on soil (inflation pressure 6 bar)

As soon as the tire model stabilizes, the steady-state tire model sinkage and rolling resistance coefficient are recorded to clarify the multi-pass effect on vehicle mobility performance as shown in Figures 18 and 19 for tire inflation pressure 6 bars.

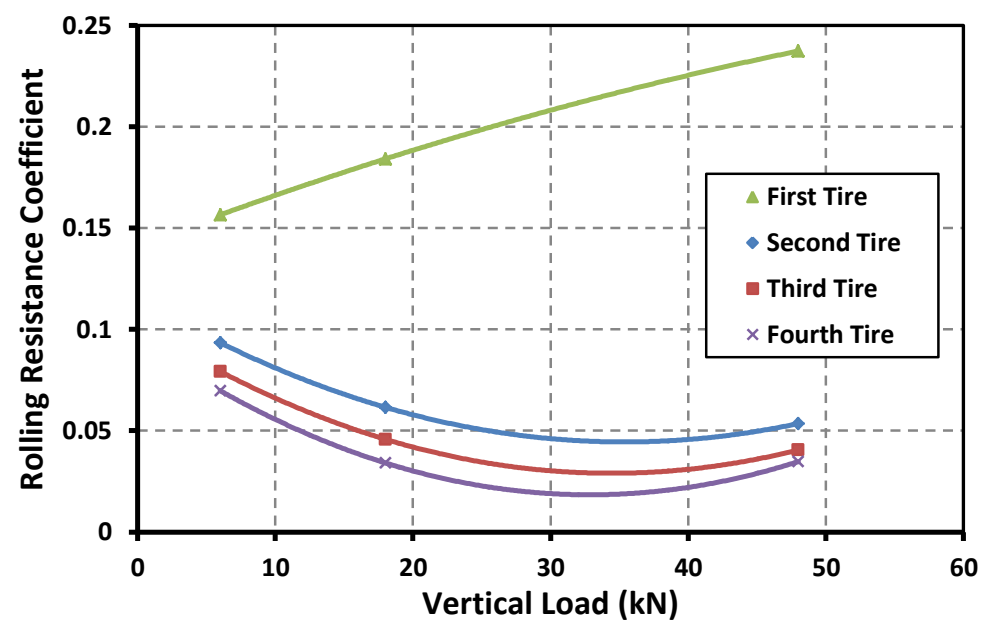

Fig 19 FEA off-road tires (4 tires) rolling resistance coefficient on soil (inflation pressure 6 bar) 


\subsubsection{Steering characteristics on soft soil for multi-axle steering}

For the steering characteristics on soil surface, the off-road tire model was developed for two steered tires with different steering angles $(\delta)$ and it will be tested for different inflation pressures (4, 6 and 8 bar) and vertical loads (6, 18 and 48kN), as seen in Figures 20 and 21.
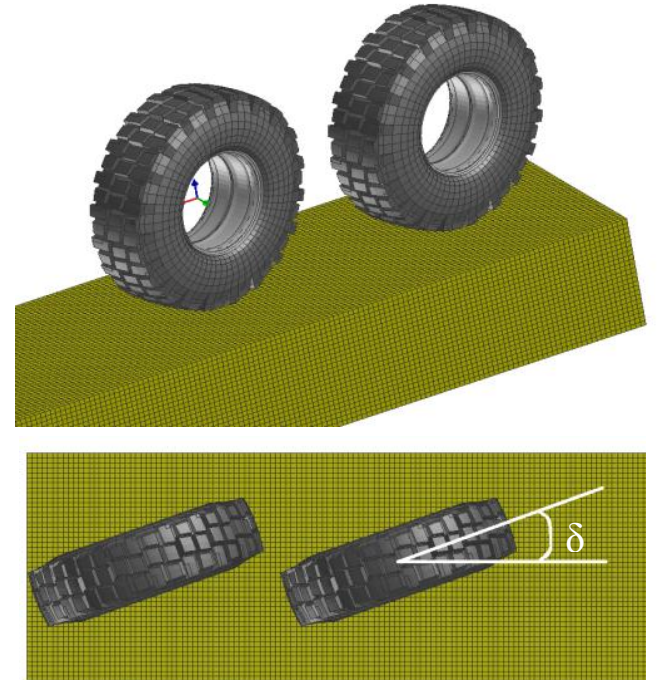

Fig. 20 FEA off-road tires (2 steered tires) on soil

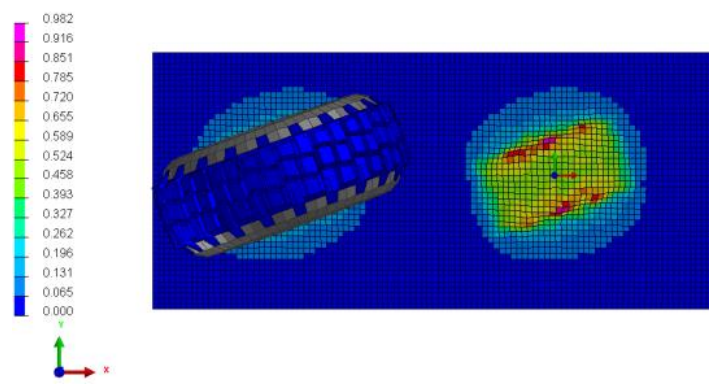

Fig. 21 FEA off-road tires ( 2 steered tires) on soil

As soon as the tire motion is stabilized, the steady-state longitudinal and lateral forces acting on the tire are recorded to calculate tire cornering characteristics.

Lateral forces and aligning moments acting on steered tires are presented in separate 3D surfaces for the first and second steering axles for each inflation pressure as seen in Figures $22,23,24$ and 25.

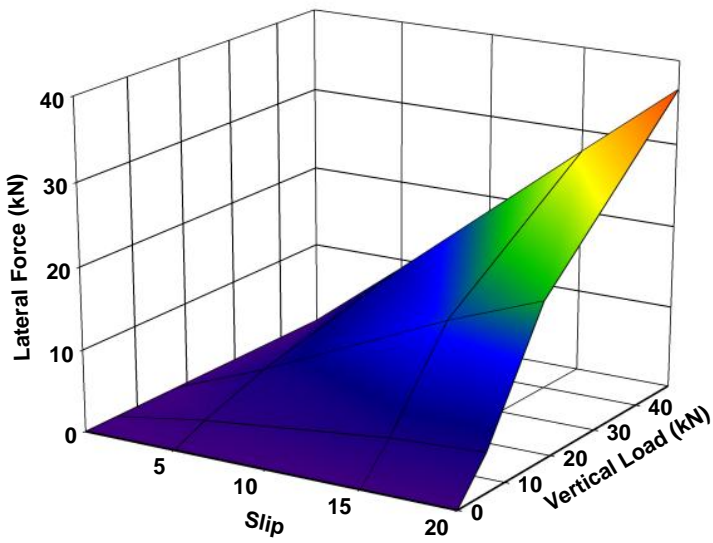

Fig. 22 Lateral forces acting on the first FEA off-road tire on soil (inflation pressure 4 bars) 


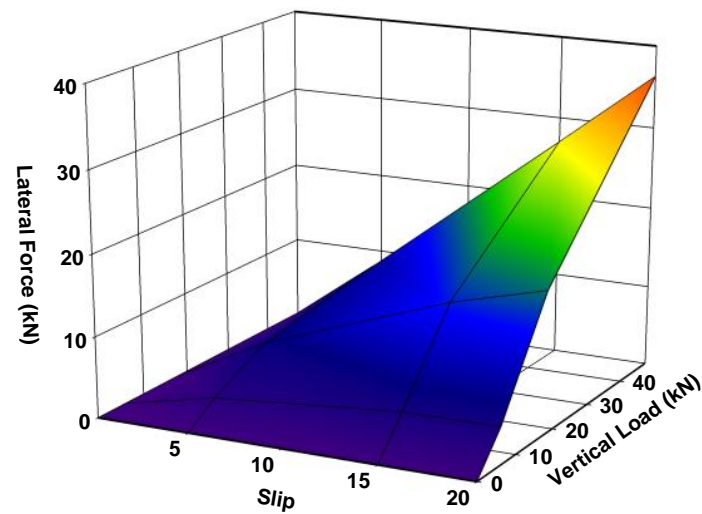

Fig. 23 Lateral forces acting on the second FEA off-road tire on soil (inflation pressure 4 bars)

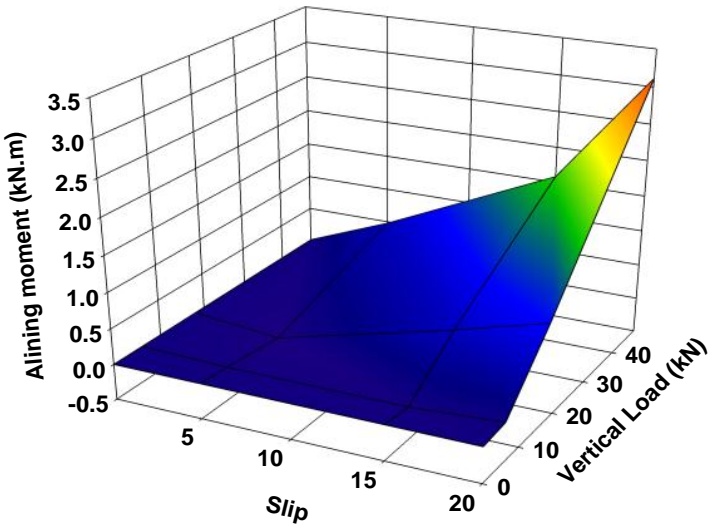

Fig. 24 Aligning moment acting on the first FEA off-road tire on soil (inflation pressure 4 bars)

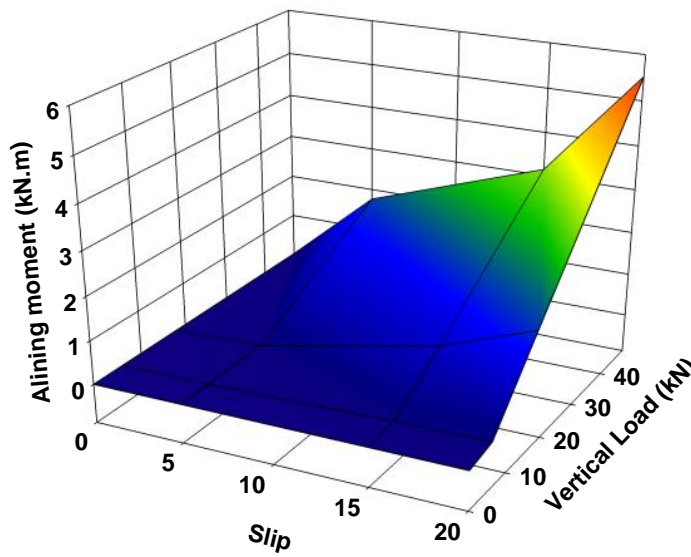

Fig. 25 Aligning moment acting on the second FEA off-road tire on soil (inflation pressure 4 bars) 


\section{FEA Tire Model Validation on Rigid Road}

As a first step for validating the vehicle model, the vehicle model was tested during lane change maneuver at different speeds using the developed FEA tire model and the tire model based on experimental measurements. Figure 27 shows how a lane- change maneuver was performed.

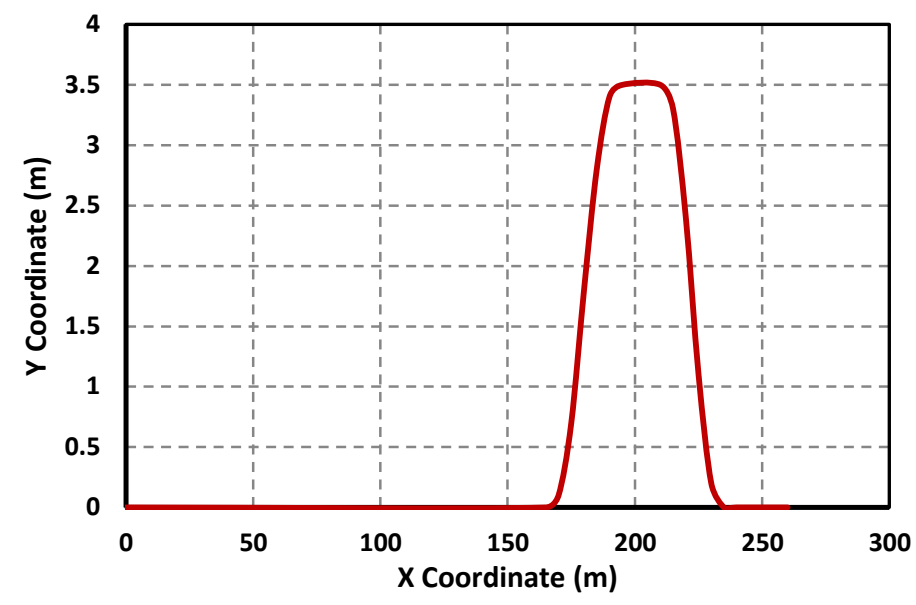

Fig. 27 Lane Change Course

Sample of the results of the simulation responses during the lane change maneuvers are given in the figures below. In this figures the vehicle speed was maintained approximately at 90 $\mathrm{km} / \mathrm{h}$ as shown in Figure 28. The vehicle yaw rate and lateral acceleration are given in Figures 29. and 30. As it can be seen excellent agreement between the measurement and simulation.

The results obtained from set of tests at 30,60 and $90 \mathrm{~km} / \mathrm{h}$ were used to validate the model using US army validation criteria. Tables 4 to 6 shows the simulation results for FEA and measured tire Kurtosis, Skewness and RMS at each speed. The FEA simulation values are within the US army criteria range. That means they are in excellent agreement with measured tire simulation results from point of the magnitute and the shape. It should be noted that the RMS is calculated only for the lateral acceleration as specified by US army.

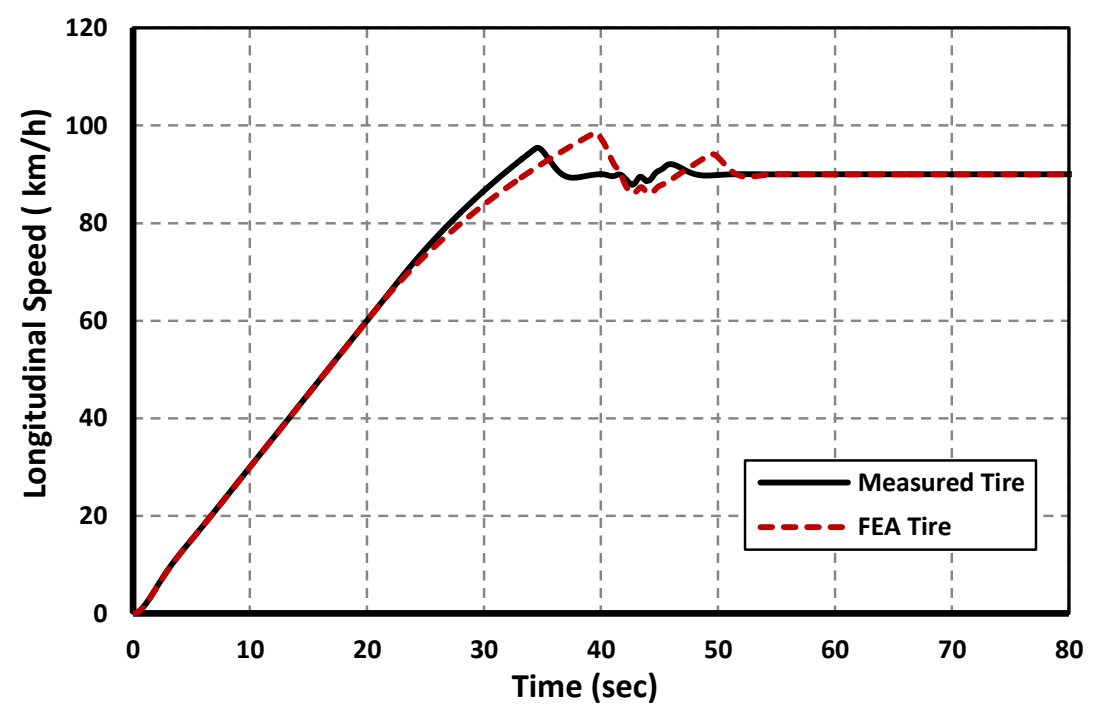

Fig. 28 Vehicle Speed 


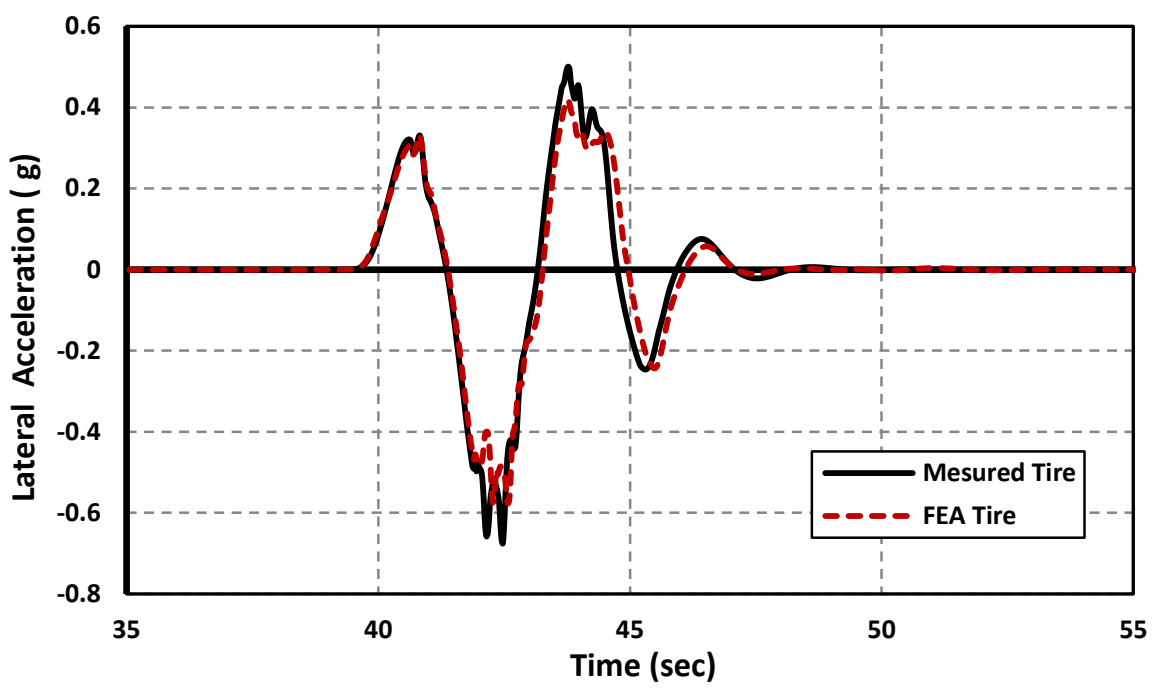

Fig. 29 Vehicle lateral acceleration time history

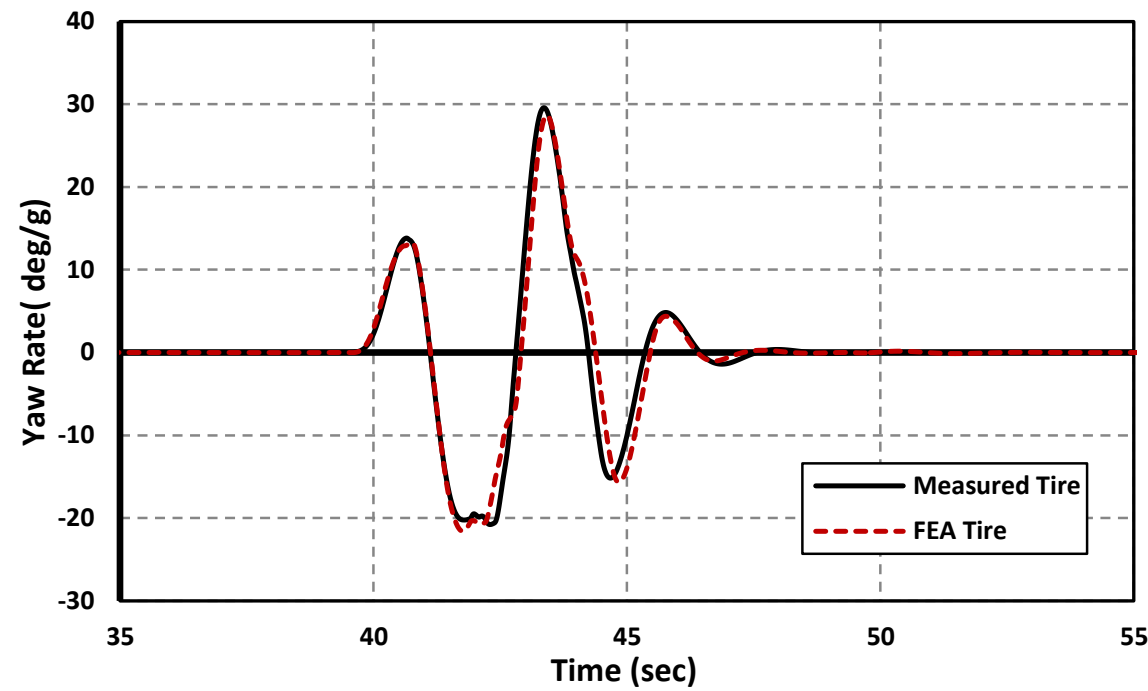

Fig. 30 Vehicle yaw rate time history

Table 4 Vehicle Speed: $30 \mathrm{~km} / \mathrm{h}$

\begin{tabular}{c|c|c|c|c}
\hline \multirow{2}{*}{} & \multicolumn{4}{|c}{ Yaw Rate } \\
\cline { 2 - 5 } & \multicolumn{4}{|c}{ US Army Validation Criteria } \\
\cline { 2 - 5 } & Measured & FEA & Min. & Max. \\
\hline Kurtosis & 16.430 & 16.053 & 8.026 & 24.079 \\
\hline Skewness & 3.707 & 3.667 & 1.834 & 5.501 \\
\hline \hline & \multicolumn{4}{|c}{ Lateral Acceleration } \\
\cline { 2 - 5 } & \multicolumn{4}{|c}{ US Army Validation Criteria } \\
\cline { 2 - 5 } & Measured & FEA & Min. & Max. \\
\hline Kurtosis & 14.539 & 14.121 & 7.060 & 21.181 \\
\hline Skewness & 1.378 & 1.013 & 1.721 & 5.163 \\
\hline RMS & 0.001 & 0.001 & 0.001 & 0.001 \\
\hline \hline
\end{tabular}


Table 5 Vehicle Speed: $60 \mathrm{~km} / \mathrm{h}$

\begin{tabular}{|c|c|c|c|c|}
\hline & \multicolumn{4}{|c|}{ Yaw Rate } \\
\hline & \multirow[b]{2}{*}{ Measured } & \multirow[b]{2}{*}{ FEA } & \multicolumn{2}{|c|}{ US Army Validation Criteria } \\
\hline & & & Min. & Max. \\
\hline Kurtosis & 10.487 & 10.231 & 5.115 & 15.346 \\
\hline \multirow[t]{4}{*}{ Skewness } & 2.875 & 2.841 & 1.420 & 4.261 \\
\hline & \multicolumn{4}{|c|}{ Lateral Acceleration } \\
\hline & \multirow{2}{*}{ Measured } & & \multicolumn{2}{|c|}{ US Army Validation Criteria } \\
\hline & & FEA & Min. & Max. \\
\hline Kurtosis & 9.210 & 8.926 & 4.463 & 13.390 \\
\hline Skewness & 2.687 & 2.646 & 1.323 & 3.969 \\
\hline RMS & 0.002 & 0.002 & 0.001 & 0.002 \\
\hline
\end{tabular}

Table 6 Vehicle Speed: 90 km/h

\begin{tabular}{c|c|c|c|c}
\hline \hline \multirow{2}{*}{} & \multicolumn{4}{|c}{ Yaw Rate } \\
\cline { 2 - 5 } & \multicolumn{3}{|c}{} & \multicolumn{2}{c}{ US Army Validation Criteria } \\
\cline { 2 - 5 } & Measured & FEA & Min. & Max. \\
\hline Kurtosis & 41.577 & 40.634 & 20.317 & 60.952 \\
\hline Skewness & 5.827 & 5.781 & 2.890 & 8.671 \\
\hline \hline
\end{tabular}

\begin{tabular}{c|c|c|c|c}
\hline \hline \multirow{2}{*}{} & \multicolumn{4}{|c}{ Lateral Acceleration } \\
\cline { 2 - 5 } & \multicolumn{3}{|c}{} & US Army Validation Criteria \\
\cline { 2 - 5 } & Measured & FEA & Min. & Max. \\
\hline Kurtosis & 42.086 & 36.827 & 18.414 & 55.241 \\
\hline Skewness & 5.852 & 5.479 & 2.739 & 8.218 \\
\hline RMS & 0.010 & 0.008 & 0.007 & 0.009 \\
\hline \hline
\end{tabular}

\section{Conclusions}

In this paper, a Finite Element Analysis (FEA) off-road tire models were developed. The FEA off-road tire models were used to examine the interaction between the tire and both rigid and soft terrain.

The developed FEA off-road tire has been validated in two different stages. First, vertical tire stiffness and cornering characteristics has been compared with published experimental data and they showed a good agreement.

Second validation stage, handling characteristics predictions of $8 \times 8$ combat vehicle model using the developed FEA off-road tire have been compared with the same vehicle model using measured tire model. US army criteria has been used to validate both simulation results at three speeds. Accordingly, the developed FEA off-road tire model can be used to predict tire-soil interactions.

The FEA off-road tire-soil model simulation results exhibited a large difference between the first and second tire in sinkage, rolling resistance and aligning moments, while differences from second to fourth are negligible, and therefore the effects of these tires may be omitted during development of a simplified tire-soil numerical model in future work. 


\section{References}

[1] Wong, J. Y., "Terramechanics and off-road vehicles", 1st ed., Elsevier Science Publishers, Amsterdam, The Netherlands, ISBN 0-444-88301-0.

[2] Yong, R. N., Fattah, E. A., Brunsinsuk, P. "Analysis and Prediction of Tyre-Soil Interaction Performance Using Finite Elements", Journal of Terramechanics, v 15, n 1, Mar, 1978, p 43-63.

[3] Hiroma, T., Wanjii, S., Kataoka, T., and Ota, Y. "Stress Analysis Using FEM on Stress Distribution Under a Wheel Considering Friction with Adhesion Between a Wheel and Soil", Journal of Terramechanics, Vol. 34, No. 4, pp. 225-233, 1997.

[4] Wallentowitz, H., Köhn, P., Holdmann, P., "Dynamic Properties of Tyres - Testing and Simulation", SAE Technical Paper 1999-01-0790, 1999.

[5] Tönük, E., Ünlüsoy, Y.S., "Prediction of automobile tire cornering force characteristics by finite element modeling and analysis", Computers \& Structures, Vol. 79, pp. 12191232, 2001.

[6] Chang, Y. P. and El-Gindy, M.,"FEA Rotating Tire Modeling for Transient Response Simulation," Paper No. IMECE2002/DE-33200, Proceedings of IMECE'02, 2002 ASME International Mechanical Engineering Congress \& Exposition, November12-17, New Orleans, Louisiana.

[7] Mehmet Akif, "Finite Element Analysis of cornering characteristics of rotating tires", PhD Thesis, September 2003.

[8] Fervers, C. W. "Improved FEM Simulation Model for Tire-Soil Interaction", Journal of Terramechanics, Vol. 41, pp. 87-100, 2004.

[9] Chae, S., El-Gindy, M., Trivedi, M., Johansson, I., and Öijer, F., (2004), "Dynamic Response Predictions of a Truck Tire Using Detailed Finite Element and Rigid Ring Models," 2004 ASME International Mechanical Engineering Congress and Exposition, Proceedings of IMECE'04, Paper No. IMECE2004-61111, Nov. 13-19, California.

[10] James Allen II, Brent Shoffner, Fredrik Öijer, Moustafa El-Gindy, Mukesh Trivedi and Inge Johansson, "Predictions of tire-terrain interaction using finite element analysis models", 2007 ASME International Design Engineering Technical Conference, September 4-7, 2007, Las Vegas, Nevada.

[11] Jeff Slade, Moustafa El-Gindy, Ryan Lescoe, Fredrik Öijer, Mukesh Trivedi and Inge Johansson, "off-road tire-soil modeling using finite element analysis technique", ASME International Design Engineering Technical Conference, August 30 - September 2, 2009, San Diego, California.

[12] Fei Han, Zheng Gui and Haosu Zhang "FEA of tire-soil model for off-road vehicle", International Conference on Mechanic Automation and Control Engineering (MACE), 26-28 June 2010, Wuhan, China.

[13] Nikola Korunović, Miroslav Trajanović , Miloš Stojković, Dragan Mišić and Jelena Milovanović.. "Finite Element Analysis of a Tire Steady Rolling on the Drum and Comparison with Experiment “, Journal of Mech. Engineering 57(2011)12, 888-897.

[14] Seokyong Chae, "Nonlinear Finite Element modeling and analysis of a truck tire", $\mathrm{PhD}$ Thesis, August 2006.

[15] Chae, S., Öijer, F., El-Gindy, M., Trivedi, M., and Johansson, I., "In-Plane and Out-ofPlane Dynamic Response Predictions of a Truck Tire Using Detailed Finite Element and Rigid Ring Models," 2005 ASME International Mechanical Engineering Congress and Exposition, Proceedings of IMECE'05, Paper No. IMECE2005-79083, Nov. 5-11, FL.

[16] Yin-ping Chang, "Nonlinear FEA rotating tire modeling for transient response simulations", PhD Thesis, May 2002, Penn State University.

[17] Wong, J. “Theory of Ground Vehicles”, John Wiley \& Sons, Inc., New York, 2008. 